\title{
Exogenous Liquidity Supply in Presence of Repudiation Risk and Private Asset Recovery.
}

\author{
Constantin T. Gurdgiev \\ Department of Economics \\ Trinity College, Dublin \\ The Open Republic Institute, Dublin \\ gurdgiec@tcd.ie
}

$3^{\text {rd }}$ Draft: June 2003

\begin{abstract}
.
Current paper proposes an extension of the seminal model by Holmstrom Tirole (1997) of the exogenous liquidity supply in presence of moral hazard to the case that includes private asset recovery under the limited liability of the entrepreneur. In our model partial private recovery applies to the financial assets that are considered to be sunk by the investors. In this context, a distressed firm seeking second round financing for its investment project is able, within a limited range of shocks, to increase its private payoff in case of the project default. As the result, unable to use these funds to raise additional liquidity, the distressed firms faces a reduced range of acceptable shock values relative to Holmstrom Tirole set up. At the same time, domestic securities markets, even in absence of aggregate uncertainty, are shown to hold insufficient liquidity. As the result, distressed firms individually are unable to counter the shocks by holding claims against other firms even in case of the financial intermediation.
\end{abstract}

JEL Classification: D82, E22, G33

Key Words: Investment, Asymmetric Information, Private Information, Repudiation Risk, Limited Liability, Aggregate Liquidity Supply.

Acknowledgements: The author wishes to thank Dr. Philip Lane, Dr. Yoonhee T. Chang, the participants in the Financial Research Workshop (Trinity College, Dublin), and the participants in the International Indistrial Organisation Society Conference (Boston, Massachusetts, 2003) for their valuable comments and suggestions. As customary, all errors and omissions are author's own. 


\section{Introduction.}

This study considers a basic question of whether or not private financial markets are sufficient in their role of creating liquidity for financially constrained investment projects. Recent microeconomic literature offers an extensive discussion of the various models of liquidity supply under the case of moral hazard, asymmetric information and adverse selection. At the same time, Holmstrom and Tirole (1994,1997), Bernanke and Gertler (1989), Kiyotaki and Moore (1995) and others have extended the microeconomic foundations for the investor/firm interaction under liquidity constraints to the macroeconomic setting.

Following the seminal work on exogenous liquidity supply by Holmstrom and Tirole (1997) (hereinafter referred to as HT), the present model extends their baseline model of investment under moral hazard to include the possibility for state-contingent partial recovery of the liquidity funds by a firm.

\section{Moral Hazard and Repudiation Risk.}

Up to date, majority of the models of liquidity crises have emphasised the importance of the trade-off between the collateral holdings of the firm and its ability to raise required liquidity in face of the adverse shocks. Thus, the level of liquidity reserves (net of original investment) determines the survivability of the firm. In the traditional models of liquidity supply in presence of moral hazard, distressed firms face incomplete markets for liquidity and thus are unable, without some form of intermediation, to complete productive investment projects. HT show that private securities markets, in case of no aggregate uncertainty, while holding sufficient liquidity funds, are unable to successfully distribute liquidity. As the result, in the simplest case of no aggregate macroeconomic uncertainty, their model restricts the economy-wide attainability of the second-best solution to the presence of intermediaries in the financial markets who act to aggregate 
and redistribute liquidity reserves from the less impacted firms to those projects that are subject to strong liquidity shocks.

Recent research in open economy macroeconomics has developed an extensive literature on the role of the limited liability in determining the direction and magnitude of the international capital flows. In most cases, few of these works discuss the possibility for presence of both moral hazard and limited liability in an economy. Even lesser attention is given in the traditional literature to the possibility of interaction between limited liability and the moral hazard.

Treating limited liability as a form of repudiation risk, one of the exceptions can be found in Lane $(1997,1999)$ extension of Gertler-Rogoff (1990) model of North-South Lending to include such risk. Assuming risk neutral borrowers and lenders, Lane (1997) shows that absent repudiation risk, the effects of moral hazard are the same in the international markets as in the closed economy setting. However, in presence of repudiation risk, the transfer from borrower to lender is limited, since the borrower always has an option of default. The resulting upper bound on repayment exacerbates moral hazard problem in the Gertler-Rogoff framework. In the models of this type, repudiation risk reduces the effective net worth of firms and thus has a negative effect on the equilibrium volume of debt that an entrepreneur can raise. Hereinafter, this is what we term the traditional effect of repudiation risk.

Another exception is provided by Farmer (1985) who develops a model of asymmetric information interactions with limited liability in the context of labour markets. Farmer endows firms with superior information set relative to both workers and creditors. As the result, optimal contracts entered into by the firm with the factor providers support lower employment equilibrium than in case of perfect capital and labour markets with symmetric information. In this context, the interaction between two risks ensures that markets are imperfect in so far as presence of information asymmetries restricts the optimal contracts to be partially non-state contingent, while the limited liability risk is state contingent. The similar rationale applies to our model except for the focus on capital 
markets instead of the labour market. Thereby we can term this effect as the interaction risk.

Extending the HT framework to include the traditional consideration of the repudiation risk alone does not qualitatively alter the conclusions of the benchmark model. The reason for the failure of the traditional repudiation risk presence in the model to generate interesting deviations from the HT model predictions lies precisely in the linear nature of the repudiation risk effects on the collateral funds available to a distressed firm. Since aggregate liquidity markets fully price such risk into firm valuation, the results of HT model will continue to hold qualitatively. However, whenever such risk is linked directly to the moral hazard effects, as shown in our model below, the solutions space for the model changes significantly. In this case presence of interaction effect ensures that the aggregate markets are characterised by non-positive capitalisation net of the funds required for continuation of the productive projects beyond the shock period.

\section{Interaction Between Various Risk Components}

Overall, growing literature in finance, starting with Borch (1962), recognises today that risks as commodities cannot be priced separately from each other. For example, Flam (2002) shows that in presence of simultaneous menu of risks, competitive equilibrium in credit markets can be achieved through a cooperative transferable utility game that resembles a form of mutual assurance company. At the same time, competitive risk pricing behaviour is shown to result in disequilibrium in credit markets. Hence, overall, interaction effects between the different risks involved in investment must be reckoned with directly both at the second best solution level and in terms of equilibrium implications. 


\section{Role of the Environment.}

None of the above mentioned models offer insights into the interaction between moral hazard and limited liability in the environment of liquidity crises that would include a link between the degree of the severity of limited liability and the nature of the project/economic environment.

In recent decades, open economies around the world have shifted away from predominantly industrial production orientation to that of services and other humancapital intensive sectors. As developments in the IT and Bio-tech sectors indicate, the new economy is characterised less by the sunken investment costs, normally associated with physical capital expenditures, and more by the possibility of project-contingent partial recovery of investment funds. For example, see Zucker et all (1998) analysis of the determinants for the location decisions of the biotechnology firms in the US. Such recovery, involving moving key talent and know-how from the failed project to the new one, in most cases is available to the entrepreneurs, who form close working links with their employees, but not the lenders, who at large remain anonymous to the employees.

Often the practice of company liquidation involves transfers of the management, $R \& D$ and technical teams to the competitors and development of joint projects that can be seamlessly integrated into the larger company structure in case of a smaller firm failure. Similarly, the downward 'feeding' practices, whereby larger firms purchase the creative and sales teams of the smaller firms in case of the latter default, are well established in the traditional advertising, creative and R\&D intensive sectors. In this context, statecontingent recovery acts to increase the degree of risk preference for entrepreneur in a way parallel to the limited liability clause in so far as it makes previously non-liquid assets, such as human capital, more liquid. It further raises the expected rate of return to the entrepreneur in case of moral hazard, since the human capital share of total capital is subject to lesser probability of seizure by the creditors. 
However state contingent recoverability of the assets, as argued below, can, or cannot, act to increase the collateral available to a firm depending on whether such recovery is possible across all states of nature during the life of the project, or is limited to the 'bad' state alone. In case where partial recovery applies to both states of nature, the entrepreneur can collateralise her share of recoverable funds accruing to the good state, thereby reducing the negative effects of moral hazard and increasing her collateral. However, whenever the partial recovery applies to the 'bad' state of nature alone, it becomes fully linked with the negative effects of the moral hazard. Limited liability then acts to ensure that entrepreneurs cannot collateralise these proceeds. The resulting decrease in the level of firm ability to raise liquidity funding in such a case can then generate the aggregate shortage of liquidity in the private securities markets. This is similar to the arguments made in Gropp et al (1996). As we show in the following model, such a shortage will result in the negative valuation of the overall markets, net of liquidity funds, thus causing the collapse of the aggregate investments pool.

Strong evidence in favour of this development can be found in the recent behaviour of the capital markets. Over the last expansion of the 1990s lenders, as well as the equity markets have shown increasing willingness to supply liquidity to the distressed firms outside the range of the shocks covered by the markets in cases of the traditional (industrial) companies. The resulting liquidity supply increase, undoubtedly can be traced to the origins and the size of the liquidity bubble in the technology sector, as well as to the high rates of money creation by the central banks around the year 2000 .

Looking further into the history of equity markets, growing independence of the stock valuations from the traditional measures of performance, such as $\mathrm{P} / \mathrm{E}$ ratios, over time can also signify the changes in the way the markets perceive the broader capital structure of the firm. Over the last 30 years, earnings, operating capacity and other factors determining the bottom line have become less important in evaluating the net worth of the companies and subsequently the net collateral funds. In many cases, these measures of economic feasibility of the firm have given way to the measurements of the R\&D productivity, managerial know-how and other 'intangible' inputs. Acquisition of such 
inputs and efforts to secure their retention within the firm today can be commonly regarded as a source of increase in firm's credit capacity. Subsequently, stock markets started to regard, at least in part, the acquisition of key scientific and managerial talent as a capital investment.

At the same time, the markets failed to account for the nature of these assets with respect to the potential role of the entrepreneur as a force aggregating these assets under her own control, outside the ability of the exogenous liquidity suppliers to monitor and collect the proceeds from such assets liquidation. As the result, as shown below, the traditional securities markets perception of the moral hazard severity fell short of the true levels of the agency problems arising from interaction of the partial private recovery of the human capital assets and the traditional moral hazard. None of these aspects are captured in the mainstream models of investment.

\section{Structure of the Paper.}

The current paper fills the aforementioned gaps by considering both the moral hazard and limited liability interactions with the overall liquidity uncertainty and the possibility for capital formation out of the liquidity funds. As a benchmark and the basis for the paper we use the model of Holmstrom and Tirole (1998). The reason for this is twofold. Firstly, since its publication, HT paper has generated a series of related and closely linked models of liquidity crises. In this context our reliance on the HT model yields straightforward comparisons across this literature. Secondly, HT model remains one of the most attractive models of the liquidity crises since its simplicity at the microfoundations level translates into high flexibility and analytical precision at the macroeconomic level as well.

In Part 1 below, following in the steps of HT, we proceed to outline a model of exogenous liquidity supply with projects heterogeneity in which moral hazard is coupled with the limited liability and partial assets recovery. Limited liability enters the model by allowing a state-contingent partial recovery of the liquidity shock funding in case of 
default of the project only. This implies that in the 'good' state of nature, when the project is seen to a successful conclusion, all liquidity funding is fully used in achieving the productive maximum. However, in case of the entrepreneur's default through moral hazard, some of the assets acquired in the process of countering the liquidity shock can be captured by the entrepreneur, but not by the investors.

art 2 of the model considers the ability of private securities markets to attain second best solution in the economy facing no aggregate uncertainty. Here we show that within a certain range of shocks that are covered in the HT benchmark model, private credit markets hold insufficient liquidity to allow for implementation of the second-best economy wide optimum. This implies that in our model dual interaction between the moral hazard, limited liability and the private recoverability of liquidity funds not only magnifies the traditional effects of private information, but also generates a second order effect that re-enforces the overall costs of liquidity risk to the domestic credit markets.

Finally, Part 3 of the model briefly adds a discussion of the differences between the statecontingent nature of the partial recovery, limited liability and its traditional specification, as well as the effects of the project size on the availability of liquidity funds. The latter link between the severity of the partial recovery effect and the nature of the economic environment offers a glimpse at the role that public information markets can play in constraining the entrepreneurial incentives to default in period 2. However we treat this part of the topic only tangentially leaving it open for the future research. 


\section{Part 1: $\quad$ Model.}

Following Holmstrom and Tirole (1997) model, assume that both investors and entrepreneurs are risk-neutral. In period 0 , entrepreneurs are endowed with financial assets in the amount of $A$ and undertake an investment project of size $I$. Hence, firms must raise $I-A$ in the first round funding. In period $I$ a liquidity shock hits requiring additional injection of liquidity in the amount of $\rho I$ in order to continue the project to period 2. In period 2, entrepreneur chooses an effort level $P_{H}$ or $P_{L}$. Conditional on the effort choice of entrepreneur, the payoffs to the project are realised.

As in HT model, investors observe final output, but are not privy to the information about the choice of effort. However, in departure from HT, entrepreneurs can privately appropriate a share of liquidity funding contingent on the moral hazard choice of low effort. Thus, the entrepreneurs can withhold $0 \leq 1-\alpha \leq 1$ share of liquidity funds in case whenever entrepreneur chooses $P_{L}$, at date 2 . The latter part of the assumption presumes that only a part of the second round funding is sunk cost, making $\rho \alpha$ (a share of the liquidity funds put up in period 1) a part of the non-recoverable cost of production. Thus, $0 \leq 1-\alpha \leq 1$ denotes the severity of limited liability effect.

When $\alpha=1$ a firm cannot privately recover any of the second round funding in case of default in period 2 (i.e. whenever $P_{L}$ is chosen). The HT model results apply fully in this case. On the other hand, in case of extreme repudiation risk, $\alpha=0$, entrepreneurs can withhold all liquidity funds from the project (whenever $P_{H}$ is chosen in period 2). As the incentives to entrepreneur to default in period 2 in this case outweigh the incentives to complete the project, for any value of shocks, the project will not obtain any financing in the second round and thus no productive optimum can be achieved by a firm facing positive liquidity demand in period 1 . 
In period 1 after the realisation of the liquidity shocks, a firm has an option to continue with the project or default. In case of default, neither entrepreneurs nor investors can recover the original investments made at date 0 . Proceeding to period 2 , the project's realised returns are $P_{i} R, i=H, L$. As in HT we restrict $P_{L} R=0$.

Depending on the choice of effort in period 2, entrepreneur will expect the return on investment given by:

$$
\begin{array}{ll}
P_{H} R_{F}(\rho) & \text { if } P_{H} \text { is chosen } \\
B+\rho(1-\alpha) & \text { if } P_{L} \text { ischosen }
\end{array}
$$

Note that throughout the following, the corresponding equations for the HT model framework will be referenced by either a superscript or a subscript $H T$.

Conditional on the choice of effort by entrepreneur, investors expected returns are:

$$
\begin{array}{ll}
{\left[P_{H} R-\rho\right]-P_{H} R_{F}(\rho)} & \text { if } P_{H} \text { ischosen } \\
0 & \text { if } P_{L} \text { ischosen }
\end{array}
$$

Figure 1 shows the time line for the life of the investment project in this model.

Since the private recovery benefits accrue solely to the entrepreneur, equation 2 is exactly the same as the corresponding return to the investor in HT model.

Controlling for the moral hazard effects and the range of shocks, partial private recovery, therefore, increases the returns to entrepreneurs at the expense of date 0 investors. The reason for this effect is that in case of moral hazard, entrepreneurs will command a higher premium on their returns in order to induce them to adopt high level of effort.

Subsequently, ceteris paribus, investors at date 0 will be required to accept lower rate of return in order to ensure that entrepreneurs do not default in period 2 by selecting a low level of effort. This is consistent with HT framework where the possibility for diluting the date 0 investments drives the firm ability to raise liquidity funding. It is also consistent broadly with the standard limited liability model. 
The partial recoverability of liquidity funding assets in its current definition supplied in equation (1) above corresponds to several definitions of limited liability (see Farmer, 1985, for example). However, it accrues in our case to a specific set of funds held by the firm, namely to the liquidity shock funding. Furthermore, it is private in nature to an entrepreneur vis-à-vis date 0 investors for whom uncertain nature of the future liquidity shocks in period 1 precludes the possibility of contractual pricing of the limited liability risk. Thus, we will interchangeably refer to this liability risk under both names.

The rationale for the assumption on the repudiation risk is given by the following. In the process of undertaking the project, all investment $(I)$ and liquidity shock funds $(\rho I)$ are used in the production process. However, a share of the liquidity funds can be recovered at the completion of the project by the entrepreneur, whenever such funds are not used to their full capacity, i.e. in case of second period default. If the entrepreneur chooses low level of effort $\left(P_{L}\right)$, she can collect the usual private rate of return $(B)$ and the remaining share of the liquidity funding. Hence, limited liability is not symmetric across the two states and two agents but is state-contingent. The components of state contingent returns add up to the total expected rate of return to firm: $R_{F}(\rho)$.

In addition we can view this ability of entrepreneur to asymmetrically capture a share of liquidity funding in the following context. Suppose following the default of the project in period 2, entrepreneur does not lose the possibility of moving on to a new investment project. The know-how acquired by entrepreneur in the process of the previous, defaulted, investment project serves her as a capital enhancing her ability to develop a new project. At the same time, the employees involved in the original project may sustain depreciation of their labour market value due to the negative signals in the previous work experience. In this case entrepreneur will be able to carry over with her the key team of employees to a new project with greater success. The lenders, at the same time may have only a limited information available to them as to the true merits of a particular employee. If the lenders information set does not exceed that of the general labour markets, the lenders will be unable to price the key employees without direct 
participation of the entrepreneur. Thus, the liquidity funds will not be subject to partial recovery by the investors.

It is worth stressing again that this effect is similar to the case of the limited liability. In particular, Gropp et all (1996) describe the following situation in the US liquidity markets:

'When debtors file under Chapter 7 of the US Bankruptcy Code, they receive a discharge from unsecured debt in return for giving up assets in excess of the relevant state's bankruptcy exemption. Several provisions of the Bankruptcy Code prevent debtors from... using private contracts as a means of voiding statutory bankruptcy exemptions. Creditors may not enforce claims against debtors' assets are covered by the Chapter 7 exemption. This provision prevents creditors from taking a blanket security interest in all debtors' possessions'(Gropp, et al, 1996, page 5).

This illustrates precisely what we refer to here as the similarity between the limited liability clause and our interpretation of the link between the asymmetric ownership (recoverability) of human capital assets of the firm. In this context, our results theoretically support empirical results attained by Gropp, et all (1996) in so far as they confirm that the firms with larger project size may benefit from greater access to the credit markets.

As in HT, entrepreneur chooses a financial contract $\mathbf{C}$ that specifies date 0 investment level $(I)$, state-contingent continuation policy $(\lambda(\rho))$ and the internal rate of return to firm $\left(R_{F}(\rho)\right)$ such that $\mathbf{C}$ solves the following problem:

$C=\arg \max I \int P_{H} R_{F}(\rho) \lambda(\rho) f(\rho) d \rho-A$

subject to: the Incentive Compatibility Constraint (ICC)

$-\rho[1-\alpha]+\Delta P R_{F}(\rho) \geq B$

and the Investors Break Even Constraint (IBEC)

$I \int\left\{\left(P_{H} R-\rho\right)-P_{H} R_{F}(\rho)\right\} \lambda(\rho) f(\rho) d \rho \geq I-A$

The details of mathematical solution are mechanical and thus relegated to the Appendix 2 below. 
In contrast with HT Program 2, equation (4.1) takes into account the presence of partial recovery in the model as well as its link with the moral hazard. At the same time, in contrast with the standard model of repudiation risk, part of liquidity funding enters as an added return to investment in the optimisation problem of the firm in a state-contingent fashion only. Hence, equation (4.1) above involves the direct link between the revenue accruing to firm, and the liquidity shock via partial recovery parameter. As in HT, the first-best cut-off value of the shock, $\rho_{1}=P_{H} R$, is independent of the partial recovery effect, $1-\alpha$. The reason for this independence is that in the first-best solution, constraints (4.1) and (4.2) ensure that the optimal contract fully prices out the limited liability clause by delivering the high level of effort choice by entrepreneur.

Formally, the above allows us to rewrite the entrepreneur's problem for the range of shocks allowing for continuation of the project as:

$C=\arg \max m(\hat{\rho}) I$

$m(\hat{\rho})=\int_{0}^{\hat{\rho}}\left(\rho_{1}-\rho\right) f(\rho) d \rho-1$

$\lambda(\rho)=1$

Again, as in HT, the first-best value of the shock satisfies the condition for the selection of high level of effort and continuation of the project. Hence, for the state-contingent continuation policy rule, the project will proceed to period $2(\lambda(\rho)=1)$ whenever $\hat{\rho}=\rho_{1}=P_{H} R$

Note that this result holds identical for the case of the benchmark HT model as well as in the case of standard repudiation risk.

From the ICC (4.1):

$R_{F}(\rho)=\frac{B}{\Delta P}+\frac{1-\alpha}{\Delta P} \rho=R_{F}^{H T}+\frac{1-\alpha}{\Delta P} \rho$

As in HT we assume that $\Delta P>0$. Equation (6) gives the return to entrepreneur sufficient to ensure adoption of high level of effort. Compared with HT, presence of partial recoverability has a singular effect on the required return to the firm. In particular, regardless of the size of the shocks faced by the firm, or the magnitude of potential private recovery, 
$R_{F}(\rho) \geq R_{F}^{H T}(\rho)$

so that in presence of repudiation risk, high realisation of liquidity shocks results in the greater incentive for entrepreneur to default and select low level of effort. The expected return to firm that would guarantee that entrepreneur sets high level of effort must be greater here than in case of HT.

Furthermore, from (6) the expected return enjoyed by the firm is increasing in the severity of the liquidity shocks. This is solely due to the increase in the return from the 'bad' state whereby the default proceeds rise relative to the proceeds from the successful completion of the project. In case of zero liquidity shock, our firm enjoys the same private rate of return as the firm in HT model, namely $\frac{B}{\Delta P}$. The same result arises whenever the partial recovery effect is absent. Hence, $\frac{1-\alpha}{\Delta P}$ can be regarded as the firm premium enjoyed by the entrepreneur in order to secure adoption of the high level of effort and to avoid the project default in period 2 in presence of the first order effect of the limited liability on moral hazard. Finally, from (6) it is clear that for any project the firm enjoys expected returns in excess of those in HT model for all values of $\rho$.

Furthermore, these returns are increasing function of the shocks magnitude, unlike in the case of HT.

By (2), (5) and (6), at date 1, an entrepreneur can pledge to an investor the expected return on investment at the rate of $\rho_{0}$, given by:

$\rho_{0}(\rho)=\rho_{1}-\rho-[B+\rho(1-\alpha)] \frac{P_{H}}{\Delta P}=\rho_{0}^{H T}(\rho)-\rho(1-\alpha) \frac{P_{H}}{\Delta P}$

Clearly, under above assumption on the effort probabilities,

$\rho_{0}(\rho) \leq \rho_{0}^{H T}(\rho)$

due to an overall higher level of moral hazard in our model. The increase in moral hazard problem is directly linked to the recoverable assets accruing to the case of higher payoff in default by an entrepreneur in period 2. Observe that here, like in HT, the pledgeable funds are a decreasing function of the severity of exogenous liquidity shocks. A rise in the liquidity shocks magnitude will, however, have a stronger effect on decreasing the 
pledgeable rate of return in our model due to the interaction between the shock magnitude and the incentives for the firm to adopt low level of effort. Similarly, an increase in the level of limited liability or partial recovery, holding constant liquidity demand, implies a fall in the pledgeable rate of return.

Overall, although we have assumed that both investors and firms are risk neutral, a limited liability clause acts to ensure that entrepreneurs will behave with some degree of risk preference. The possibility of state contingent returns from the default option leads to the lower distaste for the liquidity risk by the entrepreneur since due to the timing of the project decisions, the entrepreneur can default on the basis of assessment of the size of proceeds from partial recovery relative to the returns available in case of successful completion of the project. This is offset in the model by higher degree of risk aversion on behalf of the investors who perceive the project in our model to be at a higher moral hazard risk than in HT model for any given level of liquidity risk, due to the possibility of partial private recovery. However, period 0 investors do not know ex ante the magnitude of the shocks in period 1 thus not knowing the extent of the partial recovery effect on moral hazard. Under the perfect foresight and ICC, given by (4.1) date 0 investors will therefore supply an investment funds on the basis of the expected shocks, $\rho=E[\rho]$.

The latter aspect of lending will play an important role in the aggregate liquidity supply in private markets. To illustrate this relationship, consider the return to investor and the returns to entrepreneur as a function of the liquidity shock's magnitude. These are given by (6) and (8) and drawn in Figure 2 below.

In terms of Figure 2, decrease in the moral hazard effect of partial recovery, implied by an increase in $\alpha$, will result in the downward pivot of the firm returns line $R_{F}(\rho)$ in the direction toward the horizontal line of $R_{F}^{H T}(\rho)$. At the same time, the investor rate of return line will pivot upward from $\rho_{0}(\rho)$ toward $\rho_{0}^{H T}(\rho)$. Finally, for any level of liquidity shocks, firm returns to the project increase in the magnitude of the shock, while 
investor returns fall. The latter decline in the investor returns in faster in our case than in case of HT model.

The magnitude of shocks beyond which the project yields negative returns to investors is given, in our case by

$\rho_{11}=\frac{\rho_{11}^{H T}}{1+(1-\alpha) \frac{P_{H}}{\Delta P}}<\rho_{11}^{H T}$

Hence, the overall range of the shocks that will be covered by the exogenous liquidity suppliers in period 1 shrinks from the right relative to the HT case. However, from the perspective of date 0 investors, the presence of partial recoverability effects does not enter the determination of the cut-off point outside the ICC. Hence, the level of investment at date 0 is dependent only on the ICC, and not on the $\rho_{0}(\rho)$.

Proceeding following HT lines: by IBEC, (5), and using (6) we can express date 0 investment as:

$I=\frac{A}{\Phi(\hat{\rho})}$, where

$$
\begin{aligned}
\Phi(\hat{\rho}) & =1-\left\{\rho_{1}-\frac{B P_{H}}{\Delta P}\right\} F(\hat{\rho})+\left[1+\frac{P_{H}}{\Delta P}[1-\alpha]\right] E[\rho \mid \rho \in[0, \hat{\rho}]]= \\
& =\Phi_{H T}(\hat{\rho})+\left[\frac{P_{H}}{\Delta P}[1-\alpha]\right] E[\rho \rho \in[0, \hat{\rho}]]
\end{aligned}
$$

and for comparison, standard HT model will have:

$\Phi_{H T}(\hat{\rho})=1-\left\{\rho_{1}-\frac{B P_{H}}{\Delta P}\right\} F(\hat{\rho})+E[\rho \mid \rho \in[0, \hat{\rho}]]>\Phi(\hat{\rho})$

$\Phi(\hat{\rho})$ is the amount of internal funds a firm must put up per unit invested in order to make up for the shortfall in the second round financing, i.e. for the gap $\rho-\rho_{0}$. Note that in (12) relative to (12.a), $\left[\frac{P_{H}}{\Delta P}[1-\alpha]\right] E[\rho \mid \rho \in[0, \hat{\rho}]]>0, \forall \rho \in[0, \hat{\rho}] \wedge \forall|\alpha|<<1$, is the reserve premium that a firm in our model is required to hold in liquidity collateral over and above the HT case in order to secure the second round financing. This premium is increasing with the size of shocks at the rate of increase greater in our case than in HT 
due to dual effects of moral hazard and partial recoverability. At the same time, the premium is decreasing in $\alpha$.

Overall, (12) illustrates the point that investors at date 0 are only concerned with the ex ante expected level of shocks, since the actual shocks realisation lies outside their information set. Thus in any case where the firm experiences the shock $\rho>E[\rho \mid \rho \in(0, \hat{\rho})]$ the firm will not be able to cover the liquidity demand with the internal funds from $\Phi(\hat{\rho})$. Furthermore, although the reserve requirements are higher in our case than in case of HT, for any shocks $\rho>E[\rho \mid \rho \in(0, \hat{\rho})]$, the actual liquidity reserves net of excess demand for liquidity will be lower in our case than in case of HT.

From (12) and (12.a), by (11) we have:

$$
I_{0}<I_{0}^{H T}
$$

so that in our case, a firm with initial date 0 endowment of $A$ will be able to raise lower level of date 0 investment funds than a similar firm in HT setting. The rationale for this result is that in presence of shocks, liquidity funds that must be held in reserve are subject to more stringent collateral constraint on period 1 borrowing in case of partial recovery since the possibility to raid the liquidity funds in period 2 (adoption of $P_{L}$ ) increases internal rate of return enjoyed by entrepreneur. As the result the moral hazard problem is amplified in our case.

Following in the steps of HT model, it is straight forward to show that second best solution for the firm requires that in order to continue with the project past period 1 shocks, the cut-off point for the project liquidity requirements must be: $\rho^{*} \in\left[\rho_{0}(\rho), \rho_{1}\right]$. We omit the actual derivations since the solution arises from consideration of equations (3)-(5) and (11) following the algorithm employed by HT and reproduce here only the main steps in this algorithm (more details are supplied in the Appendix 2). Defining the internal value of the investment project to the firm as:

$U_{f}(\hat{\rho})=m(\hat{\rho}) k(\hat{\rho}) A$ from (11) and (6) we can rewrite the problem faced by the firm as: 
$C=\arg \max \left[\int_{0}^{\hat{\rho}}\left[\rho_{1}-\rho\right] f(\rho) d \rho-1\right] \frac{A}{\Phi(\hat{\rho})}$

As in HT, the solution to this problem is given by the second-best cut-off point for the shocks, namely:

$\rho^{*}=\arg \max \frac{\rho_{1}-\frac{E[\rho \mid \rho \in(0, \hat{\rho})]}{F(\hat{\rho})}}{\frac{1}{F(\hat{\rho})}+\frac{a_{1} E[\rho \mid \rho \in(0, \hat{\rho})]}{F(\hat{\rho})}}$,

where $a_{1}=1+\frac{P_{H}}{\Delta P}(1-\alpha)>1=a_{1}^{T H}$.

The first order necessary condition for the optimum is:

$\frac{1}{a_{1}} \int_{0}^{\hat{\rho}} F(\rho) d \rho=1$

Hence,

$\rho_{H T}^{*}<\rho^{*}$

for all levels of shocks below the cut-off point and above zero, and for all levels of partial recovery effect.

Note that the program above can be rewritten in following terms:

$$
\rho^{*}=\arg \min \left\{-A \frac{\rho_{1} F(\hat{\rho})-E[\rho \mid \rho \in(0, \hat{\rho})]-1}{-a_{1} E\left[\rho_{4} \rho_{C} \in_{C}(0, \hat{\rho})\right]+q_{2} \sum_{H}(\hat{\beta})-1}\right\}
$$

where $\rho_{1}-\frac{B P_{H}}{\Delta P}=a_{2}>0$.

In the above $C$ combines the first order effects of the moral hazard effect on the second best level of liquidity shock with the first order effect of partial recovery on increasing the moral hazard. $H$ at the same time denotes the second order effects of moral hazard in HT alone. The first and the second order effects predictably act in the opposing directions 
to each other, this is a result consistent with HT case. Within the first order effects, partial recovery acts in the same direction as the traditional HT effect of moral hazard, reinforcing the negative impact of the moral hazard on the second-best solution for the shock values. The reason for this is that, as was mentioned above, partial recovery amplifies the moral hazard.

In addition, observe that by (15), (16) and above, the second best cut-off value of the shocks is not independent in our case from the size of the recoverable share of the liquidity funding. In particular, an increase in $\alpha$ will result in a decrease in the $\rho^{*}$ towards the HT case of $\rho_{H T}^{*}$. The reason for this is that increase in $\alpha$ (decrease in private recoverability) will act to reduce the collateral premium requirement on the firm via reducing the negative effect of partial recoverability on moral hazard. The investment volumes will therefore increase while the social worth of the recoverable capital allocated in period 2 will decline. This implies that as recoverability falls, the required return to firm that is needed to ensure high level of effort adoption will fall, and, correspondingly, the returns to project that can be pledged to period 1 investors rise for the investors, securing an increase in the tolerable liquidity shock levels. However, the social benefits of recoverable investment fall and thus the range of optimal shocks falls as well. This channel of interaction between the moral hazard and the private recoverability is completely absent in the HT model, where the second best solution for the firm coincides with the second best solution for the investor.

By definition above, for the second-best cut-off value of the shocks, firm's net value of the project with investment at date 0 is given by $U\left(\rho^{*}\right)$, where

$$
\begin{aligned}
& U\left(\rho^{*}\right)=A \frac{\rho_{1} F\left(\rho^{*}\right)-E\left[\rho \mid \rho \in\left(0, \rho^{*}\right)\right]-1}{1-\left(\rho_{1}+\frac{B P_{H}}{\Delta P}\right) F\left(\rho^{*}\right)+a_{1} E\left[\rho \mid \rho \in\left(0, \rho^{*}\right)\right]} \\
& U_{H T}\left(\rho^{*}\right)=A \frac{\rho_{1} F\left(\rho_{H T}^{*}\right)-E\left[\rho \mid \rho \in\left(0, \rho_{H T}^{*}\right)\right]-1}{1-\left(\rho_{1}+\frac{B P_{H}}{\Delta P}\right) F\left(\rho_{H T}^{*}\right)+E\left[\rho \rho \in\left(0, \rho_{H T}^{*}\right)\right]}
\end{aligned}
$$

Hence, 
$U_{F}\left(\rho^{*}\right)>U_{F}^{H T}\left(\rho^{*}\right)$

or alternatively: $\rho_{H T}^{*}=\rho^{*}+\varepsilon$ for some $\varepsilon<0$. Once again, these results are consistent with our intuition, since amplification of the negative effects of moral hazard yields tightening of the ICC constraint and thus increases the internal net worth of the project to the firm. Continuation of the project to period 2 makes possible both higher rate of return in case of the high level of effort and the possibility of a positive, strictly increasing in the magnitude of shocks, yield from partial recovery. This fact is further highlighted by observing that for any shocks within the range of continued project, $U_{F}\left(\rho^{*}\right) \gg>0$. Overall, (19) implies that with private returns in our model in excess of the private returns in HT model for all possible values of the shocks, and in particular with private returns in our model strictly increasing in the magnitude of the shocks, the firm will have greater intrinsic value in the project that proceeds to period 2, i.e. generates some liquidity funding.

Actual solution for $\rho^{*}$ requires minimisation of the expected unit cost of investment. As in HT, the expected unit cost of investment is $\int_{0}^{\hat{\rho}} \rho f(\rho) d \rho$. However, the second best cutoff is not independent of partial recovery effects. In fact in our model the range of shocks over the second best solution can be achieved is wider than in HT model. In addition as shocks increase, the effect of the partial recoverability of second round financing rises as well relative to the first order effects of moral hazard. This implies that there exists an optimal level of allowed recovery rate for each firm, that is a function of the liquidity shocks environment. To solve for this level, consider the problem of the firm maximising the investor rate of return (to ensure that investors will supply liquidity funds), subject to ICC that will ensure that a firm will adopt high level of effort. The following proposition 1 establishes the result for individually optimal value of the recovery parameter, $\alpha^{*}$.

Proposition 1. In our model, the optimal value of recovery parameter, $\alpha^{*}$ that maximises the expected return to firm subject to the Investors Break Even Constraint is $0<<\alpha^{*}<<1$. 
Proof: Appendix 1.

The overall feasibility of the investment project in relation to the size of liquidity shocks is shown in Figure 3.

\section{Part 2. Aggregate Liquidity Markets. Case of No Aggregate Uncertainty.}

We now turn to the issue of aggregate liquidity supply to determine if, in absence of aggregate uncertainty, the securities markets hold sufficient liquidity to allow for implementation of the productive projects under idiosyncratic shocks assumption. We assume that only claims issued by the firms can be used to transfer liquidity across periods. Conforming to HT set up, consumers cannot borrow against future income. Under the assumption of risk-neutrality for consumers and entrepreneurs, rates of return in equilibrium are determined solely by the production technology described in Part 1. In absence of partial assets recovery, HT shows that private securities markets fail to distribute efficiently the liquidity reserves. At the same time, in HT the overall supply of liquidity by private asset markets is sufficient to achieve economy-wide second best solution. Hence, the main aggregation result in the HT model is that in presence of intermediaries that hold market portfolios, the private securities markets can achieve second best solution.

Let $F(\rho)$ denote the ex-ante probability of liquidity shock realisation below the value $\rho$. In this case, $F(\rho)$ also denotes the proportion of firms in economy with liquidity needs of at most $\rho I$. From Part 1 , as in HT, we can define the date 1 amount of funds needed to implement productive optimum as

$G=I \int_{0}^{\rho^{*}} \rho f(\rho) d \rho$ 
$G_{H T}=I \int_{0}^{\rho_{H T}^{*}} \rho f(\rho) d \rho<G$

By dependence of $\rho^{*}$ on the values of the partial recovery proceeds (and thus on both the share of recoverable funds and the severity of the shocks, as outlined in Part 1 above), as well as by the requirement that $\rho^{*} \in\left[0, \rho_{1}\right]$ for the second-best solution optimum, we have:

$G>G_{H T}$

Inequality (21) implies that required funds for countering liquidity shocks that ensure the productive optimum in case of partial recovery of the second period funding by the firm are higher than in case of HT. Overall, since the pedgeable return to investors in period 1 is lower in our case, the firm wishing to achieve the same level of investment as in HT model will hold lower reserves of liquidity on hand in our model. Thus the firm will need exogenous liquidity financing for the smaller shocks than in HT model. This was illustrated in the Figure 3.

The reduction in the reserve holdings of the firm in our model relative to HT arises due to three factors at play. Firstly, higher moral hazard problem will increase required rate of return to the firm and thus the incentives for the entrepreneur to invest greater share of her period 0 funds into the project. Secondly, recall that in our model the investors at date 1 will enjoy lower pledgeable returns in order to ensure the adoption of the high effort level by the entrepreneur. As the result, the firm will have to obtain greater internal funding to counter the shocks. Thirdly, when the added risk of default in period 2 is priced into the decision making of investors in period 1, the firm will be able to obtain funding for the initial investment if and only if the expected liquidity shocks are milder in our case than in the HT case. However, at date 0 there is no pricing of the added risk of partial recovery. The greater range of tolerable shocks and (17) $\rho^{*}>\rho_{H T}^{*}$ that follow from this also imply that the ex ante expected liquidity risk is lower for the continuing firms in our model than in HT model. However, as shown below, this also implies that the 
aggregate risk in the economy rises, as the probability of survival of the firms rises in our model.

With this it is straightforward to show that domestic private liquidity markets will be insufficient in ensuring that economy achieves productive optimum for the problem. To see this, consider the following financial markets solution.

Suppose a firm can continue with amounts raised to counter a given shock. Then in period 1 its market value is given by:

$P_{H}\left(R-R_{F}\right) I=\rho_{0}(\rho) I \quad$ if $P_{H}$ is set

Investors collect nothing in case whenever a firm defaults in period 1 . However, if a firm can partially recover liquidity funds from second round of financing, in case of default in period 2 (choice of $P_{L}$ ), a firm can increase its rate of return.

If the firm can collateralise these funds in period 0 borrowing to finance extra liquidity funds held after the date 0 investment, the risk of moral hazard increase due to the recoverability of liquidity assets will be fully priced into the firm valuation. In this case, the HT solution will apply.

However, if the recovery is private to the firm and the limited liability clause is operative, the firm cannot collateralise the default proceeds. As the result added risk of moral hazard is not fully priced in the investors' contracts. In this case, the investors are willing to fully dilute their claims up to the full amount of the market value of the firm that they hold, i.e. $\rho_{0}(\rho) I$. Now, recall from Part 1 that dilution amounts are given by:

$\rho_{0}(\rho) I<<\rho_{0}^{H T} I_{H T}$

so that a firm can raise less liquidity funding than in case of HT.

Next, consider $F\left(\rho^{*}\right)$ a fraction of firms who will continue on to period 2 and recall the range restrictions on $\rho^{*}$ given in Part 1. By (17):

$$
F\left(\rho^{*}\right)>F_{H T}\left(\rho^{*}\right)
$$


due to the extension of the second best optimal liquidity shocks. Hence, in absence of pricing of the partial recovery risk in date 0 investment decisions, a greater share of firms must be able to continue to period 2 in our model than in HT model to ensure the implementation of the second-best solution.

Hence, the value of external claims in economy's productive sector is given by:

$V=F\left(\rho^{*}\right) \rho_{0}(\rho) I_{0}$

$V_{H T}=F\left(\rho_{H T}^{*}\right) \rho_{H T}^{*}(\rho) I_{0}^{H T}>V$

Consider the following scenario. Suppose due to external liquidity supply expansion in period $0, I_{0}=I_{0}^{H T}$. Then, the value of liquidity in the markets in our case will be below the value of the market in HT case due to lower reserves held by the firms. The resulting shortage of funds implies that in case of the liquidity shocks in period 1, the aggregate markets will be less likely to hold the sufficient liquidity funds to continue productive projects to period 2 .

At date 1, the value of firm's external claims must be diluted by $G$ so that the total value of the market portfolio is:

$$
\begin{aligned}
S & =V-G= \\
& =I_{0} \int_{0}^{\rho^{*}}\left[\rho_{1}-\rho(1-\alpha) \frac{P_{H}}{\Delta P}-2 \rho \frac{B P_{H}}{\Delta P}\right] f(\rho) d \rho
\end{aligned}
$$

Now recalling that $\alpha<<1$ :

$$
\text { if } \quad \alpha<1+2 B-\frac{\rho_{1}}{\rho} \frac{\Delta P}{P_{H}} \Rightarrow S<0
$$

Which implies that in our model, net of dilution funds, aggregate private securities markets hold insufficient liquidity to ensure the second best solution. However, (27) holds under sufficient but not necessary condition that $\rho>\frac{\rho_{1}}{2}$. Overall we have three zones of shocks to consider:

Zone A: $\quad$ Strong Shocks Environment: $\rho>\frac{\rho_{1}}{2}$ so that $S<0$. The effect of partial recovery on increasing the moral hazard is strong enough to create excess liquidity 
demand in the aggregate markets. The second best solution is not attainable economywide for any values of recovery parameter, $\alpha<<1$.

Zone B: $\quad$ Moderate Shocks and Moderate Recovery Environment: $\rho<\frac{\rho_{1}}{2}$, but recovery parameter is relatively weak: $\alpha<1+2 B-\frac{\rho_{1}}{\rho} \frac{\Delta P}{P_{H}} \Rightarrow S<0$. This requires that $\rho>\frac{\rho_{1} \Delta P}{P_{H}(1+2 B-\alpha)}$. In this case, the markets again fail in aggregate.

Zone C: $\quad$ Weak Shocks Environment: $0<\rho<\frac{\rho_{1}}{2}-\frac{B P_{H}}{2 \Delta P}$ and Weak recovery environment: $\alpha>1+2 B-\frac{\rho_{1}}{\rho} \frac{\Delta P}{P_{H}} \Rightarrow S>0$, so that the HT result applies and the aggregate markets hold sufficient liquidity reserves to ensure the second-best solution.

Note that comparing with the individually optimal level of recovery parameter, as shown in Appendix 1, the aggregate optimality requires that $\alpha_{\text {aggregate }}^{*}=1+2 B-\frac{\rho_{1}}{\rho} \frac{\Delta P}{P_{H}}$, while individual optimum is given by:

$$
\begin{gathered}
\alpha^{*} \rho P_{H} E[\rho \mid \rho \in(0, \hat{\rho})]\left(B F(\hat{\rho})-1+\frac{1-\alpha^{*}}{\Delta P} E[\rho \mid \rho \in(0, \hat{\rho})]\right)= \\
=\rho b_{1}\left(\frac{P_{H}+\Delta P-P_{H} \Delta P}{\Delta P}\right)+(B+\rho)\left(b_{1}-1\right) E[\rho \mid \rho \in(0, \hat{\rho})] P_{H}
\end{gathered}
$$

Clearly, the absence of the ex ante expectations in the aggregate optimum reflects the efficiency of the markets, whereby the equity markets operate under complete insurance in absence of the aggregate uncertainty. Regardless of the differences, the aggregate markets optimal level of recoverability parameter is non-zero for all shocks above $\rho>\frac{B \Delta P-P_{H} \rho_{1}}{P_{H}{ }^{2}+2 P_{H}} \Delta P$, while the individual firm optimal level of recoverability is non-zero for all levels of liquidity shocks.

Overall, (27) implies and Figure 4 illustrates, that in presence of limited liability with recoverable share of liquidity funding, an economy cannot attain second best optimum by 
relying solely on the private securities markets to aggregate its liquidity in case of medium-strong shocks environment (zones A and B above). 'Lucky' firms with low realisation of liquidity shocks will hold insufficient amount of external claims to cover their demand for second round funding but will be able to obtain second round financing due to lower moral hazard problem effect of the recoverability parameter. The 'unlucky' firms on one hand will also hold insufficient liquidity reserves at date 0 , but will be unable to secure second round financing due to strong effect of recoverability on moral hazard risk.

These results stand in contrast to the HT aggregation case. In presence of partial recovery, over the plausible range of shocks the economy fails to supply exogenous liquidity sufficient to achieve the second best solution. This implies that at best the economy must rely on the lenders of last resort to allow for productive optimum to be achieved. However, such lenders are lacking in relation to the general private projects financing. In addition, the above result may provide justification for emergence of the supply credit arrangements observed in the transition economies under the liquidity crises. For example Hege and Ambrus-Lakatos (2000) attribute the emergence of interfirm supply relationships to the failure endogenous markets for provision of liquidity. They conclude that the more significant is the systematic risk in the firm's liquidity shocks exposure, the larger will be the value the entrepreneurs will attach to the nontraditional credit channels, such as trade credit arrangements. This is consistent with our aggregation results above. 


\section{Part 3. Effects of State and Project Contingency on Partial Recovery and Moral Hazard.}

An interesting consideration in the model can be given to the state and project size contingency of the partial recovery coefficient. In particular, suppose that the private recoverability of the liquidity funding is project contingent in so far as $\alpha(I)$, such that $\alpha^{\prime}(I)>0$ so that recoverability is decreasing in the level investment made at date 0 . Note that the opposite case of increasing recoverability results in the degenerate solution under which a firm has no incentives to adopt high level of effort in period 2. However, $\alpha^{\prime}(I)>0$ assumption is consistent with $P_{H}>1 / 2$ assumption that is required for $\Delta P>0$.

Overall, if partial recoverability of liquidity funding is falling in the level of investment, from part 1, the private returns enjoyed by the firm are falling as well, while the pledgeable rate of return guaranteed to the investors in period 1 is rising relative to date 0 investors' returns. The reason for this is that with decline in recoverability, moral hazard rate is falling as well. By (12) in part 1, the collateral reserve requirements are falling as well and the original period 0 investment is rising. Simultaneously, however, the decline in moral hazard effects of recoverability yields higher rate of exogenous liquidity supply to the firm facing the shocks. Asymptotically the problem converges to the case of HT as $\alpha \rightarrow 1$. This implies that with the positive effect of $I_{0}$ on moral hazard, the date 0 investors will favour higher capitalisation projects over the low capitalisation. This is matched by the willingness of firm to adopt higher effort in period 2. From (18), the net value of the project to the firm is increasing in $I_{0}$ whenever the recoverability falls with date zero investment level. As expected the diluted market portfolio following the shocks rises in value as well alleviating the risk of the liquidity funds shortage.

The link between the partial recovery coefficient and the size of investment project in turn captures in part the possibility for the variation in the public awareness about the investment project and its size. Decreasing private recoverability of second round 
financing by the firm attributable to the project size may signify in this context the fact that in modern democratic societies larger projects involve greater public scrutiny than the smaller ones. In this context the link would explain why private securities markets favoured, during the IT sector expansion, the projects with higher level of date 0 capitalisation over the smaller projects. In addition this link makes it plausible to illustrate the bias of international lenders in favour of the larger capital projects in the developing countries. In the latter context presence of private recoverability as a decreasing function of the level of initial investment yields higher returns to monitoring of the larger projects by exogenous lenders.

In addition this effect confirms empirical studies (see, for example, Gropp et al, 1996 and Berkowitz and White, 2002) that agents with larger assets (date 0 investments in the project) will be favoured by the credit markets. Furthermore, interpreting $1-\alpha$ as a measure of the degree of limited liability protection in the economy we also confirm empirical literature's conclusions that high-asset households (entrepreneurs) will have higher demand for credit in presence of higher limited liability protection, while the reverse result applies to smaller project entrepreneurs and less wealthy households. Furthermore, we confirm the result that the supply of credit (in so far as lending at period 0 concerned) rises in presence of higher bankruptcy protection (Berkowitz and White, 2002)

With this in mind we can now attempt to address a set of stylised facts concerning the entrepreneurial activity that follows the lines of de Meza and Southey (1996).

Fact 1. High drop out rates of new entrepreneurs. Traditionally two approaches account for this fact. On one hand, it is commonly argued that credit market imperfections create liquidity supply shortage to entrepreneurs facing cyclical productivity or liquidity shocks. On the other hand, de Meza dn Southey (1996) argue that excessively high degree of optimism on behalf of the borrowers leads to 'blind' entry by low quality entrepreneurs. Our results can act as a reconciliation of both opposing views. Entrepreneurs enter credit markets with asymmetric information concerning their 
ability to capture a share of liquidity funding in bad state of default. By lowering cost barriers to entry this acts to increase incentives for entrepreneurs to enter credit market. In turn such entry incentives can be interpreted as excess optimism over and above the standard model capacity to earn entrepreneurial rents. At the same time, the creditors at time 0 do possess insufficient information concerning the private returns to entrepreneurs, so that their lending decisions are subject to asymmetric information. As such information concerning both the future liquidity shock and its effect on the severity of the moral hazard risk via partial recoverability are absent in period 0 lending decisions. Collateral holdings of entrepreneurs following the first round of funding are optimistic in the direction of increasing capital outlay and subsequent liquidity shock exposure. Once again excess optimism on behalf of entrepreneurs is implicit in our model. Willingness of lenders at date 0 to supply start-up capital is also 'optimistic' in its failure to fully price the dual links between the various risks involved in the project and discussed earlier.

Fact 2. Credit loans, as opposed to equity finance, predominate as an instrument of entrepreneurial activity financing. Here again the same two opposing schools of thought can be reconciled under our model. Presence of moral hazard leads to development of contingent contracts in our model (see Farmer, 1985), while information asymmetry results in only partial contingency coverage under equity financing. In terms of classical literature, this is consistent with the limitations of equity finance vis-a-vis credit contracts. Equity financing is restricted by the state-contingency requirements of the contracts. From de Me Mezza and Southey (1996) perspective, optimising entrepreneurs in our model select maximum self-finance by over-investing their collateral in period 0 funds. Since default in period 2 is uncertain, presence of liquidation costs, as argued by de Mezza and Southey (1996), makes entrepreneurs favour the credit channel of financing over equity financing. In our model this effect is further amplified by the lowering of the cost of default to entrepreneur and increase in default risk to the lender. Equity, being non-state contingent priced asset, is thereby disfavoured even more in our model than in de Mezza and Southey (1996). 
Fact 3. Collateral provisions supplied for entrepreneurial activity financing are a decreasing function of the investment 0 funds. This aspect of the empirical world cannot be directly accounted for by the traditional models of liquidity crises under moral hazard and information asymmetries. De Mezza and Southey (1996) propose excess optimism of entrepreneurs as the potential explanation of this phenomena. In our model this stylised fact is supported by the conclusions on the credit supply asymmetries to small and large investment projects as argued above. In addition the structure of our model by allowing for complete dilution of the period 0 equity re-enforces the adverse effects of the partial repudiation on the entrepreneur 'optimism'.

Fact 4. Entrepreneurs may be denied access to credit markets even when they are willing to pay premium over and above market rate of return. In our model, an entrepreneur may be denied funding in period 1 when either shocks are strong relative to the size of the date 0 investment so that incentive to default and raid funds in period 2 is high, or where moral hazard is strong, or both. If we follow convention of the traditional investment literature, such as for example HT, a risk premium sufficient to cover moral hazard, plus repudiation risk should secure full project funding. However, in our model such risk premium will fail to price the interaction effect between the moral hazard, repudiation risk and the liquidity shock, since the three shocks are shown above to reenforce each other. The fact that, as argued above, contractual arrangements allow for only partial pricing of the repudiation risk and its links to moral hazard and liquidity shocks risk makes lenders more weary in supplying credit or equity financing at traditional rates of return.

\section{Fact 5. Businesses financed by highly secured loans are less likely to withstand} liquidity shocks. This stylised fact is supported in our model by two effects. Firstly, the ability of entrepreneur facing the liquidity shock in period 1 to dilute the claims held by investors in date 0 funding imply that self-financed projects will have lesser leverage in raising liquidity for the shock countenance. Secondly, self-financed projects in case of default after the liquidity funding is raised are more attractive to entrepreneurs with low investment outlay than to those with larger date 0 investments. In so far as self financed 
entrepreneurial activity tends to be smaller in scale, this implies that self-financed projects are harder to defend in presence of liquidity shocks and more attractive as default options for entrepreneurs.

\section{Conclusions.}

Current research extends seminal work of Holmstrom and Tirole (1997) to incorporate the limited liability clause into a model of exogenous liquidity supply in presence of moral hazard. Most commonly, limited liability is used in the contexts of bankruptcy liquidation or open economy settings. Traditional models of repudiation risk and limited liability usually rely on linear incorporation of symmetric risks for both states, assuming that only a share of final output can be withheld by the firm. As such, effects of traditional repudiation risk are captured in this model via reduction in the range of optimal liquidity shocks. The direct effect of such risk on economy is to reduce number and size of projects that pass through the shocks to completion. However, traditional repudiation risk will simply scale down the results established by HT without qualitatively altering them.

We model limited liability as a possibility that a firm can withhold a share of investment project output contingent to the state of economy and not independent of moral hazard. As such, former component of the repudiation risk represents traditional specification of the repudiation risk models. The latter component, however, generates an asymmetric effect relative to the traditional model. Once a firm, as in our model, is enabled to recover a share of financial funds put up by itself and investors in period 1 to counter liquidity shocks, we de facto allow for default of the project in period 2. This is equivalent to entrepreneur setting low level of effort, and it creates an additional interaction between the size of investment that can be applied in period 0 and the amount of funds that a firm can raise in period 1 . Over a certain range of shocks, proceeds that accrue to the firm in 
case of period 2 default, conditional on the level of repudiation risk, are below the benefits from successful completion of the project. Thus a firm will be able to raise required liquidity externally. At the same time, investors in order to finance such a firm will require it to keep greater volume of funds in period 0 in form of collateral against the possible liquidity shock. Thus firm level of investment at date 0 will also be lower over this range. Finally, a firm will be able to dilute it's outstanding value to the upper limit that combines the value of its project, less the value of the second round capital that it can capture in case of default in period 2.

These results imply that a firm will be able to continue to period 2 following the shocks realisation for the range of shocks up to the second best solution. In this context the model is similar to HT with exception that in our case we have higher level of the second best shock due to the higher internal return to the project enjoyed by the firm. Hence, the firms will raise investment at date 0 and will be able to cover a limited range of shocks bounded from the right by the second-best solution. However, overall, the economy will not be able to attain the second-best solution in case of the shocks in excess of $\frac{\rho_{1}}{2}$ for the moderately low levels of recovery parameter (zone A). As recoverable share of liquidity funding rises, the zone of shocks over which economy holds sufficient liquidity shrinks. For strong recoverability case, this zone falls to all shocks below $\frac{\rho_{1}}{2}-\frac{B P_{H}}{2 \Delta P}$ (zone $\mathrm{B}$ ). Overall, therefore, in zones A and B the economy will be characterised by the shortage of aggregate liquidity reserves.

As mentioned above, our results depend crucially on the particular structure of repudiation risk assumed. Limited liability mechanism that allows for partial recovery of the second round financing is a particular theoretic construction that is designed to capture the differences between the traditional and the new economy. In the traditional economy that rests on physical capital intensive technologies, repudiation risk applies symmetrically to both rounds of financing, since liquidity shocks can be viewed as a demand shock to capital stock. Embarking on investment project, entrepreneur sinks date 0 investment into non-recoverable assets. Subsequent liquidity shock requires that 
entrepreneur leverages the expected value of future output to raise the funds that will be re-invested into a similar sunk-type capital.

At the same time, in the new economies, investment processes become gradually more human-capital dependent. Human capital can be either non-specific or industry specific and its outputs can be viewed as intermediate inputs into investment technology. In broader application we can extend the definition of human capital to include the proprietary know-how. In this sense, liquidity shock can be viewed as an unanticipated rise in the cost of these intermediate inputs into production, or demand for them. Alternatively it can be viewed as an unexpected rise in demand for human capital faced by entrepreneur.

As recent experience in IT and biotechnology sectors suggests, human capital, proprietary know-how and other intellectual and human forms of capital can be successfully transferred by entrepreneur to a new firm or investment project in case of default of the original one in period 2. Thus a share of funds raised in period 1 to counter the unexpected capital demand shocks can be recovered by an entrepreneur. Clearly, investors in general, lacking connection with human capital and skills to utilise such capital will not be able to do so themselves.

Business literature, e.g. McKinsey Quarterly (January 2002), recognises the value of recovery of financial assets in presence of repudiation risk, as well as the ability of the firm to internally repudiate parts of operating capital that cannot be captured by investors themselves. It points out that in recent years a new industry has emerged that manages similar recovery for the lenders. Another source of evidence can be found in analysis of the carrier paths of entrepreneurs themselves. Following the collapse of capital markets for IT sector, many of the IT sector entrepreneurs have been able to move their key-staff and know-how to new enterprises. Irish examples of these 'asset recoveries' include Digital Channel Partners, Parking Partners, Remedi.com, Ebeon, Baltimore Technologies and others. 
In light of the nature of repudiation risk models, current paper only acts as an introduction to the issue of partial state-contingent recoverability of liquidity financing. In the future it can and shall be extended to the case of open capital markets. The dual effects of repudiation risk and recoverability of investment can be examined in the context of recent emphasis on FDI flows in development of the emerging markets. One interesting implication that arises in this context is that contrary to the HT set up, our model yields insufficient liquidity supply in internal securities markets. Hence, it makes it likely that in opening to the world capital markets, our economy with limited liability and partial recovery type of repudiation risk may attract substantial capital flows that would act to supplement domestic supply of liquidity. The main channel for investment in this economy in such case should be direct acquisition and other forms of FDI, in so far as equity market portfolio will be subject to the non-zero probability of the negative valuation. The reason for this assertion is that FDI characterised by the singularity of the entrepreneur-investor agent may act to internally collateralise the proceeds from partial recovery in away the traditional debt financing cannot.

Subsequently, the following research along the lines of our model shall focus on analysing its effects in the context of small open economy and work out the model implication on the direction and composition of international capital flows.

\section{References.}

Alburquerque, Rui, “The Composition of International Capital Flows: Risk Sharing Through Foreign Direct Investment" manuscript, August 2000.

Berkowitz, J. and M. White 'Bankruptcy and Small Firms' Access to Credit', NBER Working Paper 9010, July 2002.

Borch, K., Equilibrium in a reinsurance market' Econometrica (30), 3, 1962. 
Caballero, Ricardo and Arvind Krishnamurthy "International and Domectic Collateral Constraints in a Model of Emerging Market Crises", manuscript, September 2000.

Caballero, Ricardo and Arvind Krishnamurthy "International Liquidity Management: Sterilisation Policy in Illiquid Financial Markets”, manuscript, May 2000.

Cohen, David and Jeffrey Sachs, "Growth and External Debt under Risk of Debt Repudiation", European Economic Review 30, 1986: 526-560.

De Meza, D. and C. Southey 'The Borrower's Curse: Optimism, Finance and Entrepreneurship' The Economic Journal, 106, March 1996.

Eaton, Jonathan and Mark Gersowitz, "Debt with Potential Repudiation: Theory and Estimation", Review of Economic Studies 48, 1981: 289-309.

Farmer, R. E. 'Implicit Contracts with Asymmetric Information and Bankruptcy: The Effect of Interest Rates on Layoffs', Review of Economic Studies, LII, 1985.

Flam, Sjur, D. $\quad$ 'Pooling, Pricing and Trading of Risks' CESifo Working Paper 672(10), February 2002.

Gertler, Mark and Kenneth Rogoff, "North-South Lending and Endogenous Capital Market Inefficiencies", Journal of Monetary Economics26, 1990: 245-266

Gropp, R., Scholz, J. K. and M. White 'Personal Bankruptcy and Credit Supply and Demand', NBER Working Paper 5653, July 1996.

Hege, U. and L. Ambrus-Lakatos 'Trade Credit Chains and Liquidity Supply' Manuscript, ESSESC Business School, Tilburg University, 2000.

Holmstrom, Bengt and Jean Tirole, "Private and Public Supply of Liquidity", Journal of Political Economy, ??????

Hull, Leslie and Linda Tesar, "The Structure of International Capital Flow" manuscript, May 2000.

Hull, Leslie and Linda Tesar, "Risk, Specialisation and the Composition of International Capital Flows" manuscript, April 2000.

Lane, Philip ...(1997)

Lane, Philip, "North-South Lending with Moral Hazard and Repudiation Risk" Review of International Economics Volume 7, Issue 1, February 1999: 50-57.

Razin, Assaf, Sadka, Efraim and Chi-Wa Yuen, "Do Debt Flows Crowd Out Equity 
Flows or the Other Way Round?", NBER Working Paper Series, Working Paper No.7736, June 2000.

Zucker, L.G., Darby, M. R. and M. B. Brewer 'Intellectual Human Capital and the Birth of US Biotechnology Enterprises' The American Economic Review, Vol. 88, Number 1, March 1998.

\section{Appendix 1. Proof of Proposition 1.}

The firm chooses the level of recoverability to maximise the expected return to entrepreneur subject to exogenous financing availability, i.e. subject to the IBEC. The problem is given by:

$\alpha^{*}=\arg \max P_{H} \frac{B+\rho(1-\alpha)}{\Delta P}+(\rho(1-\alpha)+B)\left(1-P_{H}\right)$

subject to

$P_{H}=\frac{A+\rho_{1} F(\hat{\rho})-E[\rho \mid \rho \in(0, \hat{\rho})]-1}{b_{1}}$

where $b_{1}=F(\hat{\rho}) \frac{B}{\Delta P}+\frac{1-\alpha}{\Delta P} E[\rho \mid \rho \in(0, \hat{\rho})]$

First order condition is:

$\alpha^{*} b_{1} E[\rho \mid \rho \in(0, \hat{\rho})]=b_{1} \frac{4 P_{H}-1-2 P_{H}{ }^{2}}{P_{H}\left(2 P_{H}-1\right)}+\frac{\rho+B}{\rho}\left(b_{1} \Delta P-1\right) E[\rho \mid \rho \in(0, \hat{\rho})]$

By IBEC, probability of high effort adoption is increasing in $\alpha$. Taking the limits of the first order condition as $\alpha \rightarrow\{0,1\}$ shows that equality sign is violated in the first order condition. Hence, unambiguously, $0<<\alpha<<1$.

$(Q E D)$. 